\title{
Functional performance and 30-day postoperative mortality after emergency laparotomy - a retrospective, multicenter, observational cohort study of 1084 patients
}

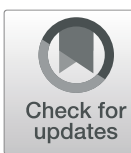

Mirjana Cihoric ${ }^{1 *}$, Line Toft Tengberg², Nicolai Bang Foss', Ismail Gögenur², Mai-Britt Tolstrup ${ }^{3}$ and Morten Bay-Nielsen ${ }^{4}$

\begin{abstract}
Background: Despite the importance of predicting adverse postoperative outcomes, functional performance status as a proxy for frailty has not been systematically evaluated in emergency abdominal surgery. Our aim was to evaluate if the Eastern Cooperative Oncology Group (ECOG) performance score was independently associated with mortality following high-risk emergency abdominal surgery, in a multicentre, retrospective, observational study of a consecutive cohort.

Methods: All patients aged 18 or above undergoing high-risk emergency laparotomy or laparoscopy from four emergency surgical centres in the Capitol Region of Denmark, from January 1 to December 31, 2012, were included. Demographics, preoperative status, ECOG performance score, mortality, and surgical characteristics were registered. The association of frailty with postoperative mortality was evaluated using multiple regression models. Likelihood ratio test was applied for goodness of fit.

Results: In total, 1084 patients were included in the cohort; unadjusted 30-day mortality was 20.2\%. ECOG performance score was independently associated with 30-day mortality. Odds ratio for mortality was $1.70(95 \% \mathrm{Cl}$ $(1.0,2.9))$ in patients with ECOG performance score of 1 , compared with $5.90(95 \% \mathrm{Cl}(1.8,19.0))$ in patients with ECOG performance score of $4(p<0.01)$. Likelihood ratio test suggests improvement in fit of logistic regression modelling of 30-day postoperative mortality when including ECOG performance score as an explanatory variable.

Conclusions: This study found ECOG performance score to be independently associated with the postoperative 30-day mortality among patients undergoing high-risk emergency laparotomy. The utility of including functional performance in a preoperative risk assessment model of emergency laparotomy should be evaluated.
\end{abstract}

Keywords: Emergency laparotomy, Frailty, 30-day mortality

\footnotetext{
* Correspondence: mirjana.cihoric.03@regionh.dk

1 Department of Anaesthesiology and Intensive Care Medicine, Hvidovre

University Hospital, Hvidovre, Kettegaard allé 30, 2650 Hvidovre,

Copenhagen, Denmark

Full list of author information is available at the end of the article
}

(c) The Author(s). 2020 Open Access This article is licensed under a Creative Commons Attribution 4.0 International License, which permits use, sharing, adaptation, distribution and reproduction in any medium or format, as long as you give appropriate credit to the original author(s) and the source, provide a link to the Creative Commons licence, and indicate if changes were made. The images or other third party material in this article are included in the article's Creative Commons licence, unless indicated otherwise in a credit line to the material. If material is not included in the article's Creative Commons licence and your intended use is not permitted by statutory regulation or exceeds the permitted use, you will need to obtain permission directly from the copyright holder. To view a copy of this licence, visit http://creativecommons.org/licenses/by/4.0/ The Creative Commons Public Domain Dedication waiver (http://creativecommons.org/publicdomain/zero/1.0/) applies to the data made available in this article, unless otherwise stated in a credit line to the data. 


\section{Introduction}

Continued increase in the number of emergency surgical procedures performed in the elderly is seen as a result of rapid expansion of the aging population, with the 65 and over share due to reach 1.6 billion by 2050 (Wang et al. 2016; He et al. 2016).

Given that emergency laparotomy is associated with a substantial degree of morbidity, 30-day mortality above 20 percent (Saunders et al. 2012; Tengberg et al. 2017a; Vester-Andersen et al. 2014) and loss of quality of life (Tolstrup et al. 2017), and accurate identification of patients who are unlikely to benefit from surgical intervention as well as those requiring more extensive observation and optimization is essential.

Dissimilarities in outcomes among elderly patients have heightened awareness that measures of performance status and function, other than chronological age alone, are important predictors of surgical outcomes (Saxton and Velanovich 2011; Gilbert et al. 2017).

Several studies identify frailty as an independent risk factor for major morbidity, mortality, protracted length of stay, and institutional discharge in elective surgical care, but also increasingly in acute surgical care (Tolstrup et al. 2017; Saxton and Velanovich 2011; Kim et al. 2014; Kenig et al. 2015; Makary et al. 2010; Hewitt et al. 2015), though with limited studies focusing solely on emergency laparotomy patients (Hamidi et al. 2018; Joseph et al. 2016; Lorenzon et al. 2017; Mogal et al. 2017; Akyar et al. 2018; Seib et al. 2018).

While significant, frailty assessments used in these studies are comprehensive and thereby potentially timeconsuming, e.g., The Modified Frailty Index (mFI) score (Panayi et al. 2018), containing 11-20 variables depending on which model is used, and Frailty Index(FI) containing over 30 variables (Joseph et al. 2016; Seib et al. 2018). A most recent study assessing frailty by Clinical frailty Scale (Parmar et al. 2019) did, however, show clear feasibility and quickness when applied to emergency laparotomy.

Functional performance has, in some studies, been indicative of poor postoperative rehabilitation (Kristensen et al. 2010; Jønsson et al. 2017), and evaluation of physical performance is considered one of the cornerstones in defining frailty (Lytwyn et al. 2017).

Based on the excellent prognostic performance of Eastern Cooperative Oncology Group Performance Status (PS) (Schiller et al. 2002), a simple physician-rated functional performance scale, the in elective patient population, the aim of this study was to evaluate if the ECOG performance Score, was independently associated with postoperative mortality following major emergency abdominal surgery, adding further to the body of knowledge and options for assessment of functional performance as a proxy for frailty.

\section{Methods}

Approval was given by the Danish Data Protection Agency and the Danish Health and Medicines Authority (207-58-0015). In consensus with the Danish law, The Regional Committee on Health Research Ethics waived the requirement for informed patient consent (H-32013-078).

The manuscript was prepared according to the Strengthening the Reporting of Observational Studies in Epidemiology (STROBE) statement (von Elm et al. 2008).

This study was a multicenter, retrospective, observational study of a consecutive cohort. The data was collected on all patients aged 18 or above undergoing high-risk emergency abdominal surgery, defined as immediate emergency laparoscopy or laparotomy due to intestinal obstruction, intestinal perforation, intestinal ischemia, or intra-abdominal bleeding, from four emergency surgical centers in the Capital Region of Denmark (covering the care of 1.62 million inhabitants), from January 1 to December 31, 2012. Definition of high-risk emergency abdominal surgery did not differ in the respective centers.

Included were all patients under suspicion of abdominal pathology requiring immediate emergency laparoscopy or laparotomy, including reoperations after elective gastrointestinal surgery. Patients with the following procedures were excluded: appendectomies, cholecystectomies, negative diagnostic laparoscopies/laparotomies, herniotomies without bowel resections, sub-acute internal hernias after gastric bypass surgery, sub-acute surgery for inflammatory bowel diseases, reoperation owing to fascial separation with no other abdominal pathology identified, and sub-acute colorectal cancer-surgery were excluded from the cohort. Sub-acute surgery was defined as surgery planned within $48 \mathrm{~h}$. Traumas, gynecological, urogenital, and other vascular pathology were also excluded, as were pregnant patients.

Surgeries were categorized as either primary laparoscopy/laparotomy or reoperations for acute complications after elective surgery. Reoperations within 30 days postoperatively after initial emergency laparoscopy/laparotomy was considered a complication and were not included.

Baseline patient characteristics were retrieved from electronic patient records, by systematically screening all patients entered in the electronic operation booking system used in all participating hospitals. Written patient records were reviewed manually for a 30-day postoperative period to identify possible complications. The surgical procedure was linked to the Danish Anaesthesia Database and the Danish Civil Registration System, thereby ensuring a hundred percent follow-up on mortality through the patients' social security number.

Data collected was age, sex, American Society of Anaesthesiologist (ASA) score (ranging from 0 (lowest risk) to 5 (highest risk), serum albumin, existence of 
comorbidity, indication for surgery (dichotomized in intestinal obstruction and all other indications, surgical characteristics (primary/re-operation, laparotomy/laparoscopy, and specific procedure), patient performance status using the Eastern Cooperative Oncology Group performance score, and preoperative sepsis score $(0$, no sepsis; 1, systemic inflammatory response syndrome (SIRS); 2, sepsis; 3, severe sepsis; 4, septic shock).

Data gathered on sepsis was done according to 2012 sepsis guidelines (Dellinger et al. 2013). In 2017, a redefinition of the guidelines was published, with the introduction of quick SOFA (qSOFA-Sepsis Related Organ Failure Assessment) score for identification of patients with heightened risk of mortality if meeting $\geq 2$ of the following criteria: respiratory rate of $22 / \mathrm{min}$ or greater, altered mentation, or systolic blood pressure of 100 mmHg or less (Rhodes et al. 2017; Singer et al. 2016). This meant that SIRS criteria were no longer used to define sepsis and septic shock. We took this under consideration when evaluating data and divided the patients in two groups, sepsis score $<2$ and $\geq 2$ when applying to logistic regression models, i.e., division between sepsis vs severe sepsis/septic shock.

In this study, frailty was assessed using the ECOG performance score as a proxy, now part of the ECOG-ACRIN Cancer Research Group (Oken et al. 1982; Buccheri et al. 1996).

The score describes a patient's level of functioning in terms of their ability to care for themselves, daily activity, and physical ability (walking, working, etc.) and ranges from 0 to 4 (Vester-Andersen et al. 2014), with 0 $=$ describing perfect health (fully active, unrestricted) and $4=$ completely disabled and cannot carry on any self-care, totally confined to bed or chair (Fig. 1).
The performance score was assigned retrospectively by a total of six clinicians from the four surgical centers, based on all available information from the medical records which included systematic recording of patient premorbidity performance and need for assistance, and incorporating these according to the ECOG performance score model.

All data collectors underwent educational training sessions to ensure that both the assessment of the performance status and complications were recorded in a standard manner using the ECOG performance score and Clavien-Dindo classification respectively. We evaluated the consistency of these recording accuracies in a random sample of 30 patients and found no important differences in assessment or classifications.

\section{Study outcome}

Primary outcome was an independent association between ECOG performance score and postoperative 30day mortality. Updated mortality data was extracted January 1, 2015.

\section{Statistical analysis}

Descriptive analysis was carried out for the entire study population. Candidate variables for mortality prediction were selected based on findings in the available literature, as well as clinical experience.

Candidate variables for inclusion in the final multivariate logistic regression model were evaluated by univariate analysis of risk of 30-day mortality, with candidates having $p$ value of $<0.25$ included in the final model. For univariate analysis, we used the Pearson chi-squared test with Yates' continuity correction where needed (Table 2).

\title{
Eastern Cooperative Oncology Group (ECOG) Performance score
}

\author{
0 - Asymptomatic (Fully active, able to carry on all predisease activities without restriction) \\ 1 - Symptomatic but completely ambulatory (Restricted in physically strenuous activity but \\ ambulatory and able to carry out work of a light or sedentary nature. For example, light \\ housework, office work)
}

2 - Symptomatic, $<50 \%$ in bed during the day (Ambulatory and capable of all self-care but unable to carry out any work activities. Up and about more than $50 \%$ of waking hours)

3 - Symptomatic, $>50 \%$ in bed, but not bedbound (Capable of only limited self-care, confined to bed or chair $50 \%$ or more of waking hours)

4 - Bedbound (Completely disabled. Cannot carry on any self-care. Totally confined to bed or chair

Fig. 1 Eastern Cooperative Oncology Group (ECOG) Performance score 
Pearson's chi-squared test and Fisher's exact tests were used for analysis of categorical variables, demographic characteristics, and comorbidities.

Continuous variables were analysed by Mann-Whitney $U$ test.

The association of ECOG performance score with 30day postoperative mortality was evaluated in a logistic regression model, with 30-day postoperative mortality as the dependent variable and ASA, indication for surgery, cardiovascular comorbidity, albumin, presence of sepsis, and ECOG performance score as independent variables. In the model, missing values were substituted by values generated by multiple imputations, with reporting based on pooled coefficients.

Likelihood ratio test was applied, comparing the goodness of fit of two logistic regression models, one with and one without ECOG performance score. Model 1 included ASA, indication for surgery, cardiovascular comorbidity, albumin, and presence of sepsis, while model 2 was added with the ECOG performance score.

The long-term survival of the cohort was illustrated with Kaplan-Meier survival statistics stratified according to the ECOG performance score.

A $p$ value of $<0.05$ was considered significant.

All analyses were performed using the $\mathrm{R}$ statistical software, an open source scripting, data analysis, and graphical environment available without cost for most operating systems (www.r-project.org).

\section{Results}

Baseline characteristics are shown in Table 1. From January 1 to December 31, 2012, 1139 patients met the inclusion criteria. Fifty-five patients were excluded due to the missing ECOG performance score data. Analyses were conducted to identify potential differences between the patients with or without missing data on several predictor variables (data not shown), and none were found.

The remaining 1084 patients composed our study population. Unadjusted 30-day postoperative mortality was $20.2 \%$.

Five hundred and twenty-two (48\%) patients had an ECOG performance score of 0 (normal activity, no restrictions), and $313(29 \%)$ had a score of 1 describing the patients as having symptomatic restrictions in strenuous activity. Twenty-three percent of the cohort had a score of 2 or more, ranging from spending up to $50 \%$ of waking hours in bed to being bedbound.

In univariate analysis, increasing age, higher ASAscore, higher ECOG performance score, sepsis, cardiovascular morbidity, low albumin level, and surgery for indications other than obstruction (i.e., ischemia and perforation) were associated with increased risk of mortality (Table 2).
In a multivariate logistic regression model, ECOG performance score was an independent predictor of 30-day postoperative mortality ( $p<0.01$, LR test). Odds ratio for mortality increased from 1.70 (95\% CI $[1.0,2.9]$ ) in patients with ECOG performance score of 1 to 5.90 $(95 \%$ CI $(1.8,19.0))$ in patients with ECOG performance score of $4(p<0.01)$ (Table 3$)$.

Figure 2 illustrates Kaplan-Meier estimated survival within days of emergency abdominal surgery stratified according to the ECOG performance score. Patients with an ECOG performance score of $0,1,2,3$, or 4 had a 12month mortality rate of $15,40,54,74$, and $80 \%$ respectively.

Figure 3 shows the increasing mortality within each ASA group, when stratified on ECOG score.

\section{Discussion}

This study found functional performance to be independently associated with mortality after high-risk emergency laparotomy or laparoscopy. Specifically, the higher the ECOG performance score, the greater the risk of 30day postoperative mortality.

Older patients represent a growing surgical population without well-defined guidelines for their management. These patients frequently present with inadequate physiological reserve to endure surgery, followed by postoperative strain (Revenig et al. 2013). This lack of reserve is often neglected or approached unsystematically. As other studies have suggested, this tendency is perhaps due to a lack of understanding of geriatric frailty, but even more so, the absence of appropriate methods for evaluating the older population in an emergent care setting. There does not seem to be a consensus on the definition or measurement of frailty (Morley et al. 2013), even in geriatric literature.

Risk assessment and prediction tools exist to help guide clinicians (Vincent and Moreno 2010), one of the most widely used is ASA, a simple but subjective assessment of preoperative risk relating to organ-specific dysfunction, identifying patients in need of a more intensive perioperative care. Other organ-specific-based scores include Physiological and Operative Severity Score for the enUmeration of Mortality and morbidity (POSSUM), Acute Physiology and Chronic Health Evaluation (APACHE II,III, IV), Simplified Acute Physiology Score (SAPS II), and Sequential Organ Failure Assessment (SOFA), primarily used in the Intensive Care Units and previously shown to be complex because of the number of variables needed to complete the score, thus making them difficult to utilize during the emergency course (Oliver et al. 2015; Chandra et al. 2009). Furthermore, tools for critical care were not originally created for perioperative risk assessment, but for comparative audit, and the raw data needed for calculation of risk is not always 
Table 1 Baseline characteristic of patients undergoing emergency high-risk abdominal surgery

\begin{tabular}{ll}
\hline Variables & Total $(n=1084)(\%)$ \\
\hline Age; years* $^{*}$ & 70 \\
$18-65$ & $413(38.1)$ \\
$66-75$ & $268(24.7)$ \\
$76-80$ & $126(11.6)$ \\
$81+$ & $277(26.3)$ \\
Female gender & $586(54.1)$
\end{tabular}

\section{ASA classification}

$$
1
$$$$
2
$$$$
3
$$$$
4-5
$$

Co-morbidities

Chronic obstructive pulmonary disease

Cardiovascular disease

Hypertension

Atrial fibrillation

Heart failure

Ischemic heart disease**

Diabetes requiring medication

Stroke

Cirrhosis

Dialysis dependent renal failure

Preoperative sepsis status

$$
\text { Non infected preoperatively }
$$

SIRS

Sepsis

Severe sepsis

Septic shock

Unknown

Preoperative performance status ECOG

0

1

Surgery characteristics

\section{Pathology:}

Perforation

Obstruction

Ischemia

$196(18.1)$

Malignancy

$211(19.5)$

Type:

Reoperation after elective surgery
Table 1 Baseline characteristic of patients undergoing emergency high-risk abdominal surgery (Continued)

\begin{tabular}{cl}
\hline Variables & Total $(n=1084)(\%)$ \\
\hline Primary & $894(82.5$ \\
Procedure & $111(10.2)$ \\
Laparoscopic surgery & $188(17.3)$ \\
Laparoscopic converted to laparotomy & $785(72.5)$ \\
Laparotomy & \\
\hline
\end{tabular}

Values in parentheses are percentages unless indicated otherwise; *values are median (i.q.r)

ASA American Society of Anaesthesiologists, SIRS Systemic Inflammatory Response Syndrome, ECOG Eastern Cooperative Oncology Group Performance Status Score.

**Previous percutaneous coronary intervention, cardiac surgery, or angina Data presented in this table has been previously published, though not to this extent or in this context in Tengberg LT, Cihoric M, and Foss NB et al. (2017). Complications after emergency laparotomy beyond the immediate postoperative period-a retrospective, observational cohort study of 1139 patients. Anaesthesia. 72 (Saunders et al. 2012):309-16

easily obtainable, particularly outside that of the ICU setting.

It is noteworthy that none of these models incorporate any assessment of overall functional capacity or frailty, as a growing body of evidence points to the importance of frailty as a predictor of outcome, in both elective and emergency care, across a wide range of medical and surgical conditions.

Only few studies regarding frailty and emergency highrisk abdominal surgery exist (Kenig et al. 2015; Hewitt et al. 2015; Parmar et al. 2019; Li et al. 2016). A study in patients undergoing emergency laparotomy found that preoperative P-POSSUM and ASA scoring predicted mortality as moderate discriminators in elderly patients undergoing an emergency laparotomy, and that the addition of frailty scoring in conjunction with PPOSSUM in this high-risk group might better identify those with a high risk of mortality (Sharrock et al. 2017).

A study from 2015 suggested that inclusion of ASA score and ECOG performance score, individually or in combination, improved risk adjustment models after cancer surgery (Young et al. 2015). A study, assessing the impact of frailty on mortality in elderly ICU patients, found that at time of admission to the ICU, the common markers of illness severity (SAPS II and SOFA) did not differ between the frail and non-frail patients (Le Maguet et al. 2014).

A recent study from 2017 (Krinsley et al. 2017), using a three-category score based on the performance of basic daily living activities, found not only that preadmission functionality score was independently associated with mortality among critically ill intensive care patients, but also found frailty score to impact the performance of APACHE IV by impacting the observed vs the predicted mortality percentage, indicating that the APACHE IV model may underestimate risk in patients with impaired functionality score. 
Table 2 Association between selected preoperative variables and postoperative Mortality. Univariate analysis

\begin{tabular}{|c|c|c|c|}
\hline & No. of patients & 30-day postoperative mortality (\%) & $p$ value \\
\hline \multicolumn{4}{|l|}{ Age $<0.0001^{*}$} \\
\hline $18-65$ & 413 & $28(6.8)$ & \\
\hline $66-70$ & 159 & $30(18.9)$ & \\
\hline $71-75$ & 133 & $29(21.8)$ & \\
\hline $76-80$ & 127 & $37(29.1)$ & \\
\hline$>80$ & 252 & $91(36.1)$ & \\
\hline Sepsis score & & & $<0.0001^{* *}$ \\
\hline $0-2$ & 1004 & $170(16.9)$ & \\
\hline $3-4$ & 80 & $45(56.3)$ & \\
\hline ECOG score & & & $<0.001 *$ \\
\hline 0 & 522 & $36(6.9)$ & \\
\hline 1 & 313 & $69(22.0)$ & \\
\hline 2 & 148 & $58(39.2)$ & \\
\hline 3 & 84 & $41(48.8)$ & \\
\hline 4 & 17 & $11(64.7)$ & \\
\hline ASA & & & $<0.0001 *$ \\
\hline 1 & 141 & $2(1.4)$ & \\
\hline 2 & 454 & $30(6.6)$ & \\
\hline 3 & 381 & 115( 30.2) & \\
\hline $4-5$ & 108 & $68(63.0)$ & \\
\hline Cardiovascular morbidity & & & $<0.0001^{* *}$ \\
\hline Yes & 540 & $149(27.6)$ & \\
\hline No & 544 & $66(12.1)$ & \\
\hline Albumin(g/L) & & & $<0.0001^{* *}$ \\
\hline Low $(<36 \mathrm{~g} / \mathrm{L})$ & 506 & $148(29.2)$ & \\
\hline Normal (36-48 g/L) & 385 & $45(11.7)$ & \\
\hline High (> $48 \mathrm{~g} / \mathrm{L})$ & 79 & $1(1.2)$ & \\
\hline Indication for surgery & & & $<0.0001^{* *}$ \\
\hline Obstruction & 494 & 68 (13.7) & \\
\hline Other & 550 & $136(24.7)$ & \\
\hline
\end{tabular}

*Pearson's chi-squared test, **Pearson's chi-squared test with Yates' continuity correction

Values in parentheses are percentages unless indicated otherwise; *values are median (i.q.r). ECOG Eastern Cooperative Oncology Group Performance Status Score, ASA American Society of Anaesthesiologists. Cardiovascular comorbidity: Hypertension, Atrial fibrillation, Heart failure, previous percutaneous coronary

intervention, cardiac surgery, or angina

A recently developed risk prediction model from the National Emergency Laparotomy Audit (NELA) does not include frailty or level of functioning prior to surgery (Eugene et al. 2018). Interestingly, they do note that the ASA score in itself did not accurately describe 30-day mortality risk in elderly patients, signifying the importance of including other relevant risk factors in risk prediction in emergency laparotomy patients. Our finding of ECOG performance score to be independently associated with 30-day postoperative mortality, and to discriminate mortality within each ASA-group, supports the relevance of including a measure of frailty in models of risk after emergency laparotomy.
Accurate risk prediction is important in the context of scientific comparison and benchmarking across different populations and studies. In a clinical context, it is relevant to inform preoperative discussions and informed consent with patients and families in especially high-risk patients, where palliative care could be a relevant option. A recent study on decision-making in emergency laparotomy found that the decision of whether to perform an emergency laparotomy is complex, with multiple influencing factors (Hendra et al. 2018). The study demonstrates a difference in decision-making and risk attitudes between surgeons; however, premorbid state or frailty was considered an important factor, as important as age, 
Table 3 Risk factors for 30-day postoperative mortality following emergency high-risk abdominal surgery. Multivariable logistic regression analysis

\begin{tabular}{|c|c|c|c|}
\hline & OR & $95 \% \mathrm{Cl}$ & $p$ value \\
\hline Age & 1.0 & $(1.01,1.05)$ & 0.0001 \\
\hline ASA 1 & 1 REF & & \\
\hline ASA 2 & 1.7 & $(0.4,7.7)$ & 0.47 \\
\hline ASA 3 & 5.6 & $(1.3,24.7)$ & 002 \\
\hline ASA 4-5 & 17.0 & $(3.8,79.0)$ & 0.001 \\
\hline Sepsis score $0-2$ & 1 REF & & \\
\hline Sepsis score $>2$ & 2.6 & $(1.4,4.7)$ & 0.002 \\
\hline Albumin low (<34 g/L) & 1 REF & & \\
\hline Albumin normal (36-48 g/L) & 0.5 & $(0.3,0.7)$ & 0.0005 \\
\hline Albumin high (> $48 \mathrm{~g} / \mathrm{L})$ & 0.1 & $(0.01,0.9)$ & 0.03 \\
\hline ECOG 0 & 1 REF & & \\
\hline ECOG 1 & 1.7 & $(1.0,2.9)$ & 0.04 \\
\hline ECOG 2 & 3.2 & $(1.78,5.8)$ & $<0.0001$ \\
\hline ECOG 3 & 3.9 & $(1.8,7.9)$ & $<0.0001$ \\
\hline ECOG 4 & 5.9 & $(1.8,19.0)$ & 0.003 \\
\hline Cardiovascular comorbidity & 0.9 & $(0.6,1.4)$ & 0.76 \\
\hline Indication for surgery (obstruction vs other) & 0.7 & $(0.6,1.4)$ & 0.14 \\
\hline
\end{tabular}

$O R$ odds ratio, $\mathrm{Cl}$ confidence interval, $A S A$ American Society of Anesthesiologists. Cardiovascular comorbidity: hypertension, atrial fibrillation, heart failure, previous percutaneous coronary intervention, cardiac surgery, or angina. ECOG Eastern Cooperative oncology Group Performance Status Score

comorbidities, and anaesthetic risk, indication that frailty is a factor to be included/evaluated in risk and prediction models.

This seems to indicate that frail patients require a different approach to care beyond assessing organ-specific dysfunction. There is a need for a more holistic approach which addresses individual needs through a goaloriented care planning process structured around functional status.

We recognize important limitations of the study. Data collection and identification of the physiological score were done retrospectively, subjecting our findings to potential bias, though mortality was not calculated at the time of data extraction. Retrospective assessment has its weaknesses; however, as ECOG already was implemented in the clinic, in form of description of the functional status during the initial assessment of the patient, an obligatory part of a patient journal, we believe that we had the relevant data on patients' possible limitations or lack of function in daily life. If the patient was unable to assist in the assessment, either relatives or information from the primary sector was available through

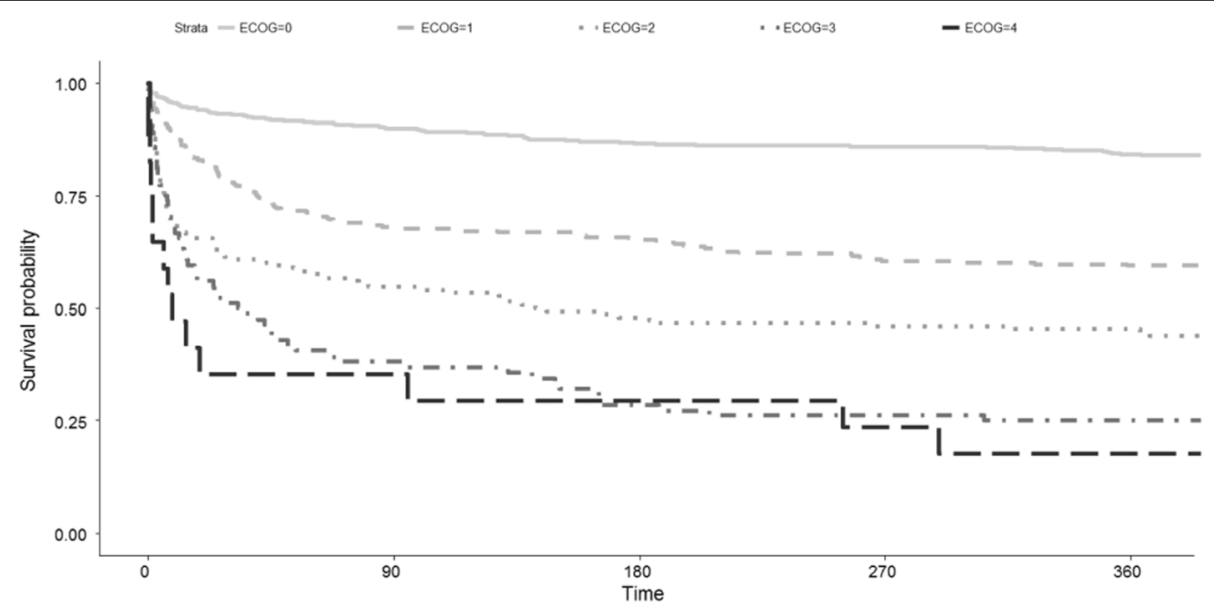

Fig. 2 Kaplan-Meier estimated survival within days of acute abdominal surgery stratified according to ECOG performance score 
ASA-score, ECOG performance score and 30 day postoperative mortality

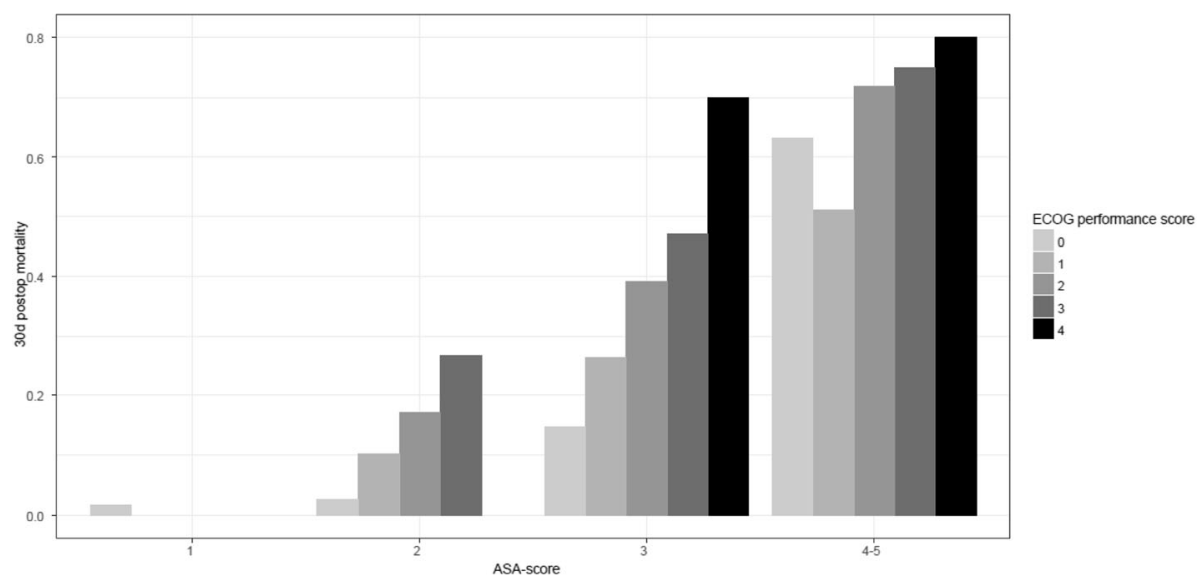

Fig. 3 Changes in mortality with increasing ECOG performance score, independently of ASA score

electronic patient records. Furthermore, several studies assessing ECOG performance score did so retrospectively (Takahashi et al. 2017; Murakawa et al. 2019). Six clinicians from four different surgical centers collected the data. By following a standardized manual, we sought to minimize the risk of inter-rater disagreement and ensure collection of high-quality data; all data collectors underwent educational training sessions to ensure that the assessment of the performance status was done in a standard manner. Fifty-six patients had missing data, meaning that description of their performance status was not registered in the initial assessment upon hospitalization; this is, however, not as large a group as we might have expected. Analyses were conducted to identify potential differences between the patients with or without missing data on several predictor variables (data not shown), and none were found. However, these findings ought to be confirmed in future prospective trials.

Furthermore, the logistic regression analysis did not take into account the experience of the primary surgeon and anaesthesiologist, as well as timing of the surgery or whether surgery was performed during the night or daytime. This could have had a potential impact on the postoperative outcome. Lastly, data from this study are from 2012. Data in this study is older, yes, and the mortality is high. Around that time, a focus shifted on this patient group and several groups, AHA group from Hvidovre, Denmark (Tengberg et al. 2017b), as well as ELPQuiC- group from the UK (Huddart et al. 2015), designed multimodal protocols for improving the outcomes, and these studies have now resulted in awareness and integration of standardized process pathways reducing postoperative mortality to app. 10-18\%, depending on study. Our result straddles the time period where these interventions were performed.
The mortality of 9.5 percent in NELA study (NELA study n.d.),is the result of significant focus on optimizing the care pathway in emergency laparotomy. The primary problem in comparing postoperative mortality directly between different nations/surgical cultures is patient selection, which can introduce a selection bias. Patient selection is potentially impacted by professional cultural differences, as demonstrated in comparisons between US and UK cohorts (Markar et al. 2019a; Markar et al. 2019b). This has recently been described in a recent cohort study of the "NoLap" population, which represent data from a single UK centre with $30 \%$ of candidates for mergency laparotomy not receiving surgery due to perceived futility, which may impact overall mortality (Mcllveen et al. 2019).

Although formal studies in "NoLap" is almost nonexistent, the culture in Denmark mandates surgery before assessment of futility. However, there is no data to support this statement.

Another interesting notion, in the NoLap cohort, is that the functional independence was $81 \%$ in the group having laparotomy compared to $30 \%$ in the group not having surgery, and as such functional assessment is of great importance in triage decisions, although it would seem that it is used somewhat arbitrarily at present.

We also recognize several strengths: this is, to our knowledge, the first study to examine ECOG performance score in an exclusively emergent setting, focusing on emergency high-risk abdominal surgery. Recent studies do examine frailty in emergency general surgery (Joseph et al. 2016; Mogal et al. 2017; Akyar et al. 2018; Panayi et al. 2018), however, the definition of emergency general surgery differs. While the majority of these studies group appendectomies, cholecystectomies and intestinal obstruction, pathophysiology of these conditions cannot be compared. Also, the sample size for ECOG 4- 
5 was small, and the stratification by ASA could be considered unreliable.

In an emergency setting, comprehensive frailty screening instruments such as Fried Frailty Phenotype (Makary et al. 2010) assessing weight loss, grip strength, exhaustion, physical activity, gait speed, or Canadian Study of Health and Aging Frailty Index (Rockwood et al. 2005) with a count of 70 factors assessing frailty, are probably not feasible due to patients acute condition and time sensitive nature of the emergent case. In studies mentioned above, Modified Frailty Index and Frailty Index was used, and while these frailty assessments are perhaps less subjective, they are more comprehensive.

While functional performance cannot stand alone as a proxy for frailty, it is indicative of a potentially frail individual. Incorporating physical performance measures in evaluation of frailty has shown to be highly predictive of clinical outcome of elderly surgical patients presenting for emergency orthopedic surgery (Gary n.d.; Parker and Palmer 1993; Foss et al. 2006), even more so than ASA. Furthermore, recent study (Parmar et al. 2019) of a large cohort found Rockwood Clinical Frailty Score (CFS) quick and feasible in an emergency laparotomy cohort, a score incorporating functional performance in assessing frailty, much like ECOG performance score. Our study supports these findings, and further underlines the importance of functional performance in patients undergoing emergency laparotomy. Furthermore, this study also incorporates all patients aged 18 or over, stressing the fact that frailty is not only a function of the chronological age; part of the utility of a reliable frailty scale is in identifying younger patients at risk for adverse postoperative outcomes.

Also, this multicentre study contains large homogenous dataset with a $100 \%$ follow-up of postoperative mortality.

In conclusion, growing body of evidence supports the notion that preoperative functional performance assessments are feasible and provide critical information in regard to frailty beyond the traditional surgical risk assessments. This study found ECOG performance score to be independently associated with postoperative 30day mortality among patients undergoing emergency laparotomy.

\section{Acknowledgements}

Not applicable.

\section{Authors' contributions}

M.C. (conception and design, acquisition of data, analysis and interpretation of data, drafting the article, and final approval of the version to be published). L.T.T. (conception and design, acquisition of data, revising the article critically for important intellectual content, and final approval of the version to be published). N.B.F. (conception and design, analysis and interpretation of data, revising the article critically for important intellectual content, and final approval of the version to be published). I.G. (conception and design, revising the article critically for important intellectual content, and final approval of the version to be published). M.B.T. (conception and design, revising the article critically for important intellectual content, and final approval of the version to be published. M.B.N. (contribution to conception and design, acquisition of data, analysis and interpretation of data, revising the article critically for important intellectual content, and final approval of the version to be published). All authors are in an agreement to be accountable for all aspects of the work, thereby ensuring that questions related to the accuracy or integrity of any part of the work are appropriately investigated and resolved. The authors read and approved the final manuscript.

Funding

No funding was received.

Availability of data and materials

The data set used and/or analyzed during current study are readily available from the corresponding author on reasonable request.

Ethics approval and consent to participate

Approval was given by the Danish Data Protection Agency and the Danish Health and Medicines Authority (207-58-0015). In consensus with the Danish law, The Regional Committee on Health Research Ethics waived the requirement for informed patient consent (H-3-2013-078).

\section{Competing interests}

There are no known potential or real conflicts of interest.

\section{Author details}

${ }^{1}$ Department of Anaesthesiology and Intensive Care Medicine, Hvidovre University Hospital, Hvidovre, Kettegaard allé 30, 2650 Hvidovre,

Copenhagen, Denmark. ${ }^{2}$ Department of Surgery, Center for Surgical Science, Zealand University Hospital, Koege, Denmark. ${ }^{3}$ Department of Gastrointestinal Surgery, Copenhagen University Hospital, Herlev, Copenhagen, Denmark. ${ }^{4}$ Department of Gastrointestinal Surgery, Hvidovre University Hospital, Copenhagen, Denmark.

Received: 26 October 2019 Accepted: 24 March 2020

Published online: 05 May 2020

\section{References}

Akyar S, Armenia SJ, Ratnani P, Merchant AM. The impact of frailty on postoperative cardiopulmonary complications in the emergency general surgery population. Surg J (New York, NY). 2018;4(2):e66-77. Available from: http://www.ncbi.nlm.nih.gov/pubmed/29796424.

Buccheri G, Ferrigno D, Tamburini M. Karnofsky and ECOG performance status scoring in lung cancer: a prospective, longitudinal study of 536 patients from a single institution. Eur J Cancer Part A. 1996;32(7):1135-41.

Chandra A, Mangam S, Marzouk D. A review of risk scoring systems utilised in patients undergoing gastrointestinal surgery. J Gastrointest Surg. 2009 [cited 2013 Mar 7];13(8):1529-38. Available from: http://www.ncbi.nIm.nih.gov/ pubmed/19319612.

Dellinger RP, Levy MM, Rhodes A, Annane D, Gerlach H, Opal SM, et al. Surviving sepsis campaign. Crit Care Med. 2013;41(2):580-637. Available from: papers2://publication/doi/10.1097/CCM.0b013e31827e83af.

Eugene N, Oliver CM, Bassett MG, Poulton TE, Kuryba A, Johnston C, et al. Development and internal validation of a novel risk adjustment model for adult patients undergoing emergency laparotomy surgery: the National Emergency Laparotomy Audit risk model. Br J Anaesth. 2018;121(4):739-48. Available from: http://www.ncbi.nlm.nih.gov/pubmed/30236236.

Foss NB, Kristensen MT, Kehlet $\mathrm{H}$. Prediction of postoperative morbidity, mortality and rehabilitation in hip fracture patients: the cumulated ambulation score. Clin Rehabil. 2006;20(8):701-8 Available from: http://www.ncbi.nlm.nih.gov/ pubmed/16944827.

Gary R. Evaluation of frailty in older adults with cardiovascular disease: incorporating physical performance measures. J Cardiovasc Nurs. n.d.;27(2): 120-31 Available from: http://www.ncbi.nlm.nih.gov/pubmed/22334147.

Gilbert T, Neuburger J, Kraindler J, Keeble E, Smith P, Ariti C, et al. Title page Title: Development and validation of a frailty risk score focusing on older people in acute care settings using electronic hospital records. Lancet. 2017;6736(18): 1-8 Available from: https://doi.org/10.1016/S0140-6736(18)30668-8.

Hamidi M, Zeeshan M, O'Keeffe T, Nisbet B, Northcutt A, Nikolich-Zugich J, et al. Prospective evaluation of frailty and functional independence in older adult 
trauma patients. Am J Surg. 2018;216(6):1070-5. Available from: http://www ncbi.nlm.nih.gov/pubmed/30343875.

He W, Goodkind D, Kowal P. An Aging World : 2015 International Population Reports. Aging (Albany NY). 2016;165:95-16-1.

Hendra L, Hendra T, Parker SJ. Decision-making in the emergency laparotomy: a mixed methodology study. World J Surg [Internet]. 2018 19; [Epub ahead of print]. Available from: http://www.ncbi.nlm.nih.gov/pubmed/30456483.

Hewitt J, Moug SJ, Middleton M, Chakrabarti M, Stechman MJ, McCarthy K. Prevalence of frailty and its association with mortality in general surgery. Am J Surg. 2015;209(2):254-9.

Huddart S, Peden CJ, Swart M, McCormick B, Dickinson M, Mohammed MA, et al. Use of a pathway quality improvement care bundle to reduce mortality after emergency laparotomy. Br J Surg. 2015;102(1):57-66.

Jønsson LR, Ingelsrud LH, Tengberg LT, Bandholm T, Foss NB, Kristensen MT. Physical performance following acute high-risk abdominal surgery: a prospective cohort study. Can J Surg 2017;60(6):12616. Available from: http://www.ncbi.nlm.nih.gov/pubmed/29171831.

Joseph B, Zangbar B, Pandit V, Fain M, Mohler MJ, Kulvatunyou N, et al. Emergency general surgery in the elderly: too old or too frail? J Am Coll Surg. 2016;222(5):805-13. Available from: http://www.ncbi.nlm.nih.gov/ pubmed/27113515.

Kenig J, Zychiewicz B, Olszewska U, Barczynski M, Nowak W. Six screening instruments for frailty in older patients qualified for emergency abdominal surgery. Arch Gerontol Geriatr. 2015;61(3):437-42.

Kim S, Han H-S, Jung H, Kim K, Hwang DW, Kang S-B, et al. Multidimensional frailty score for the prediction of postoperative mortality risk. JAMA Surg. 2014;149(7):633-40. Available from: http://archsurg.jamanetwork.com/article. aspx?doi=10.1001/jamasurg.2014.241

Krinsley JS, Wasser T, Kang G, Bagshaw SM. Pre-admission functional status impacts the performance of the APACHE IV model of mortality prediction in critically ill patients. Crit Care 2017;21(1):110. Available from: http://ccforum. biomedcentral.com/articles/10.1186/s13054-017-1688-z.

Kristensen MT, Foss NB, Ekdahl C, Kehlet H. Prefracture functional level evaluated by the New Mobility Score predicts in-hospital outcome after hip fracture surgery. Acta Orthop. 2010;81(3):296-302. Available from: http://www.ncbi. nlm.nih.gov/pubmed/20450426

Le Maguet P, Roquilly A, Lasocki S, Asehnoune K, Carise E, Saint Martin M, et al. Prevalence and impact of frailty on mortality in elderly ICU patients: A prospective, multicenter, observational study. Vol. 40, Intensive Care Medicine. 2014. p. 674-82. Available from: http://link.springer.de/link/service/ journals/00134/index.htm\%5Cnhttp://ovidsp.ovid.com/ovidweb.cgi?T= JS\&PAGE=reference\&D=emed 16\&NEWS $=\mathrm{N} \& A N=53064859$.

Li JL, Henderson MA, Revenig LM, Sweeney JF, Kooby DA, Maithel SK, et al. Frailty and one-year mortality in major intra-abdominal operations This study was presented at the World Congress of Endourology in London in October 2015. J Surg Res. 2016;203(2):507-12.e1. https://doi.org/10.1016/j.jss.2016.03. 007. Epub 2016 Mar 22

Lorenzon L, Costa G, Massa G, Frezza B, Stella F, Balducci G. The impact of frailty syndrome and risk scores on emergency cholecystectomy patients. Surg Today. 2017;47(1):74-83. Available from: http://www.ncbi.nlm.nih.gov/ pubmed/27241560

Lytwyn J, Stammers AN, Kehler DS, Jung P, Alexander B, Hiebert BM, et al. The impact of frailty on functional survival in patients 1 year after cardiac surgery. J Thorac Cardiovasc Surg [Internet]. 2017;154(6):1990-9. Available from: http://www.ncbi.nlm.nih.gov/pubmed/28734627.

Makary MA, Segev DL, Pronovost PJ, Syin D, Bandeen-Roche K, Patel P, et al. Frailty as a predictor of surgical outcomes in older patients. J Am Coll Surg. 2010;210:901-8

Markar SR, Vidal-Diez A, Holt PJ, Karthikesalingam A, Hanna GB. An international comparison of the management of gastrointestinal surgical emergencies in Octogenarians-England versus United States: a national population-based cohort study. Ann Surg. 2019b; Available from: http://www.ncbi.nlm.nih.gov/ pubmed/31188204.

Markar SR, Vidal-Diez A, Patel K, Maynard W, Tukanova K, Murray A, et al. Comparison of surgical intervention and mortality for seven surgical emergencies in England and the United States. Ann Surg. 2019a;270(5):806-12. Available from: http://www.ncbi.nlm.nih.gov/pubmed/31567504.

Mcllveen EC, Wright E, Shaw M., Edwards J, Vella M, Quasim T, et al. A prospective cohort study characterising patients declined emergency laparotomy: survival in the "NoLap" population. Anaesthesia. 2019;anae.
14839. Available from: https://onlinelibrary.wiley.com/doi/abs/10.1111/ anae.14839.

Mogal H, Vermilion SA, Dodson R, Hsu F-C, Howerton R, Shen P, et al. Modified Frailty Index predicts morbidity and mortality after pancreaticoduodenectomy. Ann Surg Oncol. 2017;24(6):1714-21. Available from: http://www.ncbi.nlm.nih.gov/pubmed/28058551.

Morley JE, Vellas B, Abellan van Kan G, Anker SD, Bauer JM, Bernabei R, et al. Frailty consensus: a call to action. J Am Med Dir Assoc. 2013;14(6):392-7.

Murakawa Y, Sakayori M, Otsuka K. Impact of palliative chemotherapy and best supportive care on overall survival and length of hospitalization in patients with incurable Cancer: a 4-year single institution experience in Japan. BMC Palliat Care. 20193;18(1):45. Available from: http://www.ncbi.nlm.nih.gov/ pubmed/31159782.

National Emergency Laparotomy Audit (NELA). Fourth Patient NELA report. https://www.nela.org.uk/reports.

Oken MM, Creech RH, Tormey DC, Horton J, Davis TE, McFadden ETCP. Toxicity and response criteria of the Eastern Cooperative Oncology Group. Am J Clin Oncol. 1982;5(6):649-55.

Oliver CM, Walker E, Giannaris S, Grocott MPW, Moonesinghe SR. Risk assessment tools validated for patients undergoing emergency laparotomy: A systematic review. Br J Anaesthesia. 2015;115:849-60.

Panayi AC, Orkaby AR, Sakthivel D, Endo Y, Varon D, Roh D, et al. Impact of frailty on outcomes in surgical patients: A systematic review and meta-analysis. Am J Surg 2018; Available from: http://www.ncbi.nlm.nih.gov/pubmed/30509455.

Parker MJ, Palmer CR. A new mobility score for predicting mortality after hip fracture. J Bone Joint Surg Br. 1993;75(5):797-8 Available from: http://www. ncbi.nlm.nih.gov/pubmed/8376443.

Parmar KL, Law J, Carter B, Hewitt J, Boyle JM, Casey P, et al. Frailty in Older Patients Undergoing Emergency Laparotomy: Results From the UK Observational Emergency Laparotomy and Frailty (ELF) Study. Ann Surg. 2019; Available from: http://www.ncbi.nlm.nih.gov/pubmed/31188201.

Revenig LM, Canter DJ, Taylor MD, Tai C, Sweeney JF, Sarmiento JM, et al. Too frail for surgery? Initial results of a large multidisciplinary prospective study examining preoperative variables predictive of poor surgical outcomes. J Am College of Surgeons. 2013;217:665-70.

Rhodes A, Evans LE, Alhazzani W, Levy MM, Antonelli M, Ferrer R, et al. Surviving sepsis campaign: international guidelines for management of sepsis and septic shock: 2016. Intensive Care Med. 2017:43(3):304-77.

Rockwood K, Song X, MacKnight C, Bergman H, Hogan DB, McDowell I, et al. A global clinical measure of fitness and frailty in elderly people. CMAJ. 2005; 173(5):489-95.

Saunders DI, Murray D, Pichel AC, Varley S, Peden CJ. Variations in mortality after emergency laparotomy: the first report of the UK emergency laparotomy network. Br J Anaesth. 2012;109(3):368-75.

Saxton A, Velanovich V. Preoperative frailty and quality of life as predictors of postoperative complications. Ann Surg. 2011;253(6):1223-9. Available from: http://content.wkhealth.com/linkback/openurl?sid=WKPTLP:landingpage\&an= 00000658-201106000-00026

Schiller JH, Harrington D, Belani CP, Langer C, Sandler A, Krook J, et al. Comparison of four chemotherapy regimens for advanced non-small-cell lung cancer. N Engl J Med. 2002 10;346(2):92-8. Available from: http://www. ncbi.nlm.nih.gov/pubmed/11784875.

Seib CD, Rochefort H, Chomsky-Higgins K, Gosnell JE, Suh I, Shen WT, et al. Association of Patient Frailty With Increased Morbidity After Common Ambulatory General Surgery Operations. JAMA Surg. 2018;153(2):160-8. Available from: http://www.ncbi.nlm.nih.gov/pubmed/29049457.

Sharrock AE, McLachlan J, Chambers R, Bailey IS, Kirkby-Bott J. Emergency abdominal surgery in the elderly: can we predict mortality? World J Surg 2017:41(2):402-9.

Singer M, Deutschman CS, Seymour CW, Shankar-Hari M, Annane D, Bauer M, et al. The third international consensus definitions for sepsis and septic shock (Sepsis-3). JAMA. 2016;315(8):801-10. Available from: http://jama. jamanetwork.com/article.aspx?doi=10.1001/jama.2016.0287.

Takahashi M, Takahashi M, Komine K, Yamada H, Kasahara Y, Chikamatsu S, et al. The G8 screening tool enhances prognostic value to ECOG performance status in elderly cancer patients: A retrospective, single institutional study. PLoS One. 2017;12(6):e0179694. Available from: http://www.ncbi.nlm.nih.gov/ pubmed/28640844.

Tengberg LT, Bay-Nielsen M, Bisgaard T, Cihoric M, Lauritsen ML, Foss NB, et al. Multidisciplinary perioperative protocol in patients undergoing acute high- 
risk abdominal surgery. Br J Surg. 2017;104(4):463-71. https://doi.org/10.1002/ bjs.10427. Epub 2017 Jan 23.

Tengberg LT, Cihoric M, Foss NB, Bay-Nielsen M, Gögenur I, Henriksen R, et al. Complications after emergency laparotomy beyond the immediate postoperative period - a retrospective, observational cohort study of 1139 patients. Anaesthesia. 2017a;72(3):309-16.

Tolstrup MB, Watt SK, Gögenur I. Morbidity and mortality rates after emergency abdominal surgery: an analysis of 4346 patients scheduled for emergency laparotomy or laparoscopy. Langenbeck's Arch Surg. 2017;402(4):615-23.

Vester-Andersen M, Lundstrom LH, Moller MH, Waldau T, Rosenberg J, Moller AM. Mortality and postoperative care pathways after emergency gastrointestinal surgery in 2904 patients: a population-based cohort study. Br J Anaesth. 2014;112(5):860-70

Vincent J-L, Moreno R. Clinical review: scoring systems in the critically ill. Crit Care. 2010;14(2):207.

von Elm E, Altman DG, Egger M, Pocock SJ, Gøtzsche PC, Vandenbroucke JP, et al. The Strengthening the Reporting of Observational Studies in Epidemiology (STROBE) statement: guidelines for reporting observational studies. J Clin Epidemiol [Internet]. 2008;61(4):344-9. Available from: http://www.ncbi.nlm.nih.gov/pubmed/18313558.

Wang H, Naghavi M, Allen C, Barber R, Bhutta ZA, Carter C, et al. Global, regional, and national life expectancy, all-cause mortality, and cause-specific mortality for 249 causes of death, 1980-2015: a systematic analysis for the Global Burden of Disease Study 2015. Lancet. 2016;388(10053):1459-544.

Young J, Badgery-Parker T, Dobbins T, Jorgensen M, Gibbs P, Faragher I, et al. Comparison of ECOG/WHO performance status and ASA score as a measure of functional status. J Pain Symptom Manage. 2015;49(2):258-64.

\section{Publisher's Note}

Springer Nature remains neutral with regard to jurisdictional claims in published maps and institutional affiliations.

Ready to submit your research? Choose BMC and benefit from:

- fast, convenient online submission

- thorough peer review by experienced researchers in your field

- rapid publication on acceptance

- support for research data, including large and complex data types

- gold Open Access which fosters wider collaboration and increased citations

- maximum visibility for your research: over $100 \mathrm{M}$ website views per year

At $\mathrm{BMC}$, research is always in progress.

Learn more biomedcentral.com/submissions 